\title{
Descentralización macrorregional estratégica para el desarrollo sostenible del Perú (1979-2014)
}

\section{RESUMEN}

Se determina que la macrorregión concebida como extensa unidad territorial transversal es una solución para el desarrollo sostenible del Perú. Se identifica que la regulación de la delimitación territorial para la regionalización es ineficaz. La asignación centralizada del canon no permite el desarrollo equitativo y sostenible a los gobiernos regionales. Se demuestra que la macrorregión, es una subdivisión geopolítica que abarca varias regiones favoreciéndose tanto económico y socialmente. Se establece que el marco normativo es indispensable.

Palabras Clave: Regionalización; descentralización; macrorregionalización; delimitación territorial transversal.

\section{Descentralization macro regional strategic sustainable development of Peru (1979-2014)}

\begin{abstract}
It is determined that the Macro Region conceived as an extensive transverse territorial unit is a solution for the sustainable development of Peru. It is identified that the regulation of territorial delimitation for regionalization is ineffective. The centralized allocation of the royalty does not allow for the equitable and sustainable development of regional governments. It is shown that the Macro Region, is a geopolitical subdivision that covers several regions favoring both economically and socially. It establishes that the regulatory framework is indispensable.
\end{abstract}

KEYwORDs: Regionalization; decentralization; Macro regionalization; Transverse territorial delimitation 


\section{Introducción}

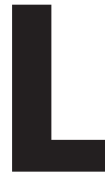

a regionalización es un proceso que se ha instaurado en el Perú desde la dación de la Constitución de 1979, por cierto, con largas interrupciones durante la década del 90. En que se impuso la Constitución de 1993 vigente. El propósito es logar una sólida e ininterrumpida descentralización a través de unidades territoriales transversales con autonomía administrativa presupuestal y de gestión.

El Perú, después de la independencia en 1821 fue dividido en departamentos, los cuales incrementaron su número de once en 1822 a veinticuatro en 1980. Como la concentración del poder político y económico se incrementaba en Lima capital, muchas administraciones trataron de descentralizar el país, aunque con poco éxito (Schönwälder 2004: 94).

Después de 10 años de gobierno militar, en el gobierno del Gral. Bermúdez se dio la constituyente presidida por Haya de la Torre donde se redactó y se promulgo la Constitución Peruana de 1979. Esta Constitución contuvo previsiones para la descentralización del poder mediante la creación de regiones autónomas, pero éstas no fueron implementadas (O’Neill 2000: 197).

Durante los últimos ańos del primer gobierno de Alan García (1985-1990), el régimen estableció en rápida decisión 12 regiones autónomas el 20 de enero de 1989. los gobiernos regionales carecieron de recursos fiscales propios, así que dependieron de la bondad del gobierno central para los fondos (O'Neill 2000:199).

Las 12 Regiones Políticas creadas durante el gobierno aprista (1989-1991) fueron:

1. Región Amazonas

2. Región Andrés Avelino Cáceres

3. Región Arequipa

4. Región Chavín

5. Región Grau

6. Región Inka

7. Región José Carlos Mariátegui

8. Región Los Libertadores-Wari

9. Región Lima

10. Región Nororiental del Marañón

11. Región Ucayali

12. Región Víctor Raúl Haya de la Torre

Las elecciones presidenciales de 1990 estuvieron marcadas por el descrédito al sistema partidario, lo evidencia la elección de Alberto Fujimori, un candidato independiente. Fujimori improvisado gobernante retuvo las transferencias financieras a los gobiernos regionales y luego, el 29 de diciembre de 1992 después de imponer un estado autocrático con el golpe del 05.04.1992, las reemplazó con los Consejos Transitorios de Administración Regional (CTAR) creados para cada departamento. Habiendo disuelto el congreso durante la crisis constitucional de 1992 como se ha dicho, Fujimori convocó a elecciones para una Asamblea Constituyente la cual promulgó la constitución de 1993. Este nuevo texto incluyó previsiones para la creación de regiones con gobiernos elegidos y autónomos, pero no fueron llevadas a cabo. La Ley Marco de Descentralización promulgada el 30 de enero de 1998, confirmó la permanencia de los consejos transitorios, ahora bajo la supervisión del Ministerio de la Presidencia (Schönwälder (2004: 195-196)

En noviembre de 2000, Fujimori renuncia a la presidencia debido a acusaciones de autoritarismo, corrupción y violaciones de derechos humanos. BBC News (2007). Después de un gobierno de transición dirigido por Valentín Paniagua, Alejandro Toledo fue elegido presidente para el periodo 2001-2006 en un contexto que incluyó la creación de gobiernos regionales. La nueva administración dispuso el marco legal para las nuevas divisiones administrativas en la Ley de Bases de la Descentralización, promulgada el 17 de julio de 2002, y la Ley orgánica de Gobiernos Regionales promulgada el 19 de noviembre de 2002. Flamantes Gobiernos Regionales fueron elegidos el 20 de noviembre de 2002, uno por cada departamento y uno en la Provincia Constitucional del Callao, y se le dio a la Municipalidad Metropolitana de Lima rango de Gobierno regional a fin de que la provincia de Lima, que contiene a la capital, fuera destinada a no conformar parte de ninguna de las futuras regiones.

En las elecciones de 2002, muchos de los gobiernos regionales fueron a partidos de la oposición, con doce ganadas por el APRA y solo una por Perú Posible, el partido del presidente Alejandro Toledo. (Oficina Nacional de Procesos Electorales (2008). La combinación de una fuerte oposición y un gobierno deficiente llevaron a la preocupación sobre una inminente crisis política, sin embargo, este no fue el caso ya que los nuevos gobiernos regionales fueron absorbidos por problemas locales y mostraron poca iniciativa en la política nacional (Monge, 2008: 34). 


\section{Fundamentación teórica}

En este contexto se indica que la regionalización «es un componente estratégico de la descentralización. Se propone crear en el país unidades territoriales de carácter intermedio transversal-vale decir, regioneslas cuales tienen autoridad o jurisdicción, gobiernos regionales dotados de autonomía, competencias y rentas, las mismas que deben ser creadas por mandato constitucional y legal» (Grupo Propuesta Ciudadana, 2008: 8). Debemos tener en cuenta que, en el Perú existe una clara diferenciación regional por su base geográfica y proceso histórico, en virtud a ello se puede señalar que una de las características del proceso de descentralización es la regionalización, lo cual significa conformar una nueva forma de organizar el territorio que supere las limitaciones del actual trazo departamental. Por otro lado, es conveniente señalar que la regionalización no es necesariamente una condición previa para el desarrollo ni para la desconcentración económica, en la medida en que no ocurran cambios en la estructura económica a nivel espacial que modifiquen el actual patrón de crecimiento y distribución. Aunque sí es una de las posibilidades más importantes para democratizar el Estado y cambiar la relación Estado-Sociedad, puesto que permitiría la creación de nuevas instituciones capaces de descentralizar recursos y capacidades de decisión (Gonzáles de Olarte, E., 1989: 8).

Considerando la región como uno de los elementos principales para lograr la descentralización, se le define como la parte del territorio estructurada en forma racional y objetiva, dotado de recursos naturales, provisto de una red eficiente de vías de comunicación y de un conjunto de centros poblados con condiciones de participar en la tarea del desarrollo nacional. Así, se entiende que en este ámbito territorial deben hallarse integrados los elementos geográficos, históricos, culturales, económicos, administrativos y políticos que sirven de soporte y lubricación al conjunto social (Marcos J., 1996: 2).

Queda claro que el proceso de regionalización no se basa en crear regiones autárquicas que puedan generar conflictos entre el gobierno central y los gobiernos regionales, sino todo lo contario, tiene como objetivo crear polos de desarrollo en todo el país, en virtud de realizar un balance al excesivo centralismo que tiene con el gobierno regional. Razón por lo cual, el objetivo del proceso de regionalización es la descentralización del Estado y del gobierno, a partir de la cual se espera una descentralización y desconcentración económica, es decir, la transformación socio-económica de las regiones, bajo el supuesto de que los cambios que disminuirían las situaciones conflictivas existentes entre el Estado centralista y las Regiones deben hacerse desde el Estado. En consecuencia, su transformación significaría la transformación de la sociedad (Gonzáles de Olarte E., 1989: 17).

En ese sentido, es necesario señalar que el objetivo último de la regionalización es generar un nuevo ordenamiento territorial que permita reducir las profundas desigualdades espaciales que se originan en la gran concentración del poder económico y político de nuestra sociedad. Una visión de estas características nos permite entender que solo estamos dando los pasos iniciales de un proceso que se proyecta en el mediano y largo plazo. Transformar una sociedad tan centralista como la peruana requiere cambios sostenidos en la estructura económica, política, institucional y cultural. En ese sentido, como sostiene Aspur (2005: 16), la regionalización debe llevarse adelante como una política de Estado.

Según el artículo $6^{\circ}$ de la Ley de Base de la Regionalización señala que la finalidad del Gobierno Regional es lograr el desarrollo integral y armónico de la región, con el concurso y la participación de la población, y con sujeción a la Constitución, la Ley y los planes nacionales de desarrollo.

Por tanto, es importante entender que la conformación de regiones o regionalización en el Perú, como un proceso aún en desarrollo mediante el cual se busca lograr la conformación de regiones como divisiones políticas del país, integradas para instruir Gobiernos Regionales con autonomía económica y política que permitan descentralizar la acción del Estado, orientada a su Desarrollo Sostenible.

La más conocida definición de Desarrollo Sostenible es la de la Comisión Mundial sobre Ambiente y Desarrollo (Comisión Brundtland) que en 1987 definió el Desarrollo Sostenible como: «El desarrollo que asegura las necesidades del presente sin comprometer la capacidad de las futuras generaciones para enfrentarse a sus propias necesidades» (Dublín (1987). Según este planteamiento el desarrollo sostenible tiene que ver con:

- Satisfacer a las necesidades del presente, fomentando una actividad económica que suministre los bienes necesarios a toda la población mundial. 
La Comisión resaltó "las necesidades básicas de los pobres del mundo, a los que se debe dar una atención prioritaria».

- Satisfacer las necesidades del futuro, reduciendo al mínimo los efectos negativos de la actividad económica, tanto en el consumo de recursos como en la generación de residuos, de tal forma que sean soportables por las próximas generaciones. Cuando nuestra actuación supone costos futuros inevitables (por ejemplo, la explotación de recursos naturales no renovables), se deben buscar formas de compensar totalmente el efecto negativo que se está produciendo (por ejemplo, desarrollando nuevas tecnologías que sustituyan el recurso gastado)

Las características que debe reunir un desarrollo para que lo podamos considerar sostenible son:

- Busca que la actividad económica mantenga o mejore el sistema ambiental.

- Asegura que la actividad económica mejore la calidad de vida de todos, no solo de unos pocos selectos.

- Uso de los recursos eficientemente.

- Promueve el máximo de reciclaje y reutilización.

- Pone su confianza en el desarrollo e implantación de tecnologías limpias.

- Restaura los ecosistemas dañados.

- Promueve la autosuficiencia regional

- Reconoce la importancia de la naturaleza para el bienestar humano.

Para llevar a cabo el desarrollo sostenible es necesario el cambio de mentalidad, acentuando las relaciones entre el hombre y la naturaleza que lleva a pensar que:

- Los hombres civilizados estamos fuera de la naturaleza y se afectan sus leyes.

- El éxito de la humanidad se basa en el control y el dominio de la naturaleza.

- La Tierra tiene una ilimitada cantidad de recursos a disposición de los humanos.

Estos planteamientos se encuentran firmemente asentados en el hombre, especialmente en la cultura occidental que, desde hace unos cuatro siglos, ha visto el éxito de una forma de pensar técnica y centrada en el dominio de la naturaleza por el hombre.

El punto de vista del desarrollo sostenible pone el énfasis en que debemos plantear nuestras actividades «dentro" de un sistema natural que tiene sus leyes. Debemos usar los recursos sin trastocar los mecanismos básicos del funcionamiento de la naturaleza.

Un cambio de mentalidad es lento y difícil. Requiere afianzar unos nuevos valores. Para hacerlo son de especial importancia los programas educativos y divulgativos. Tiene mucho interés dar a conocer ejemplos de actuaciones sostenibles, promover declaraciones públicas y compromisos políticos, desarrollar programas que se propongan fomentar este tipo de desarrollo.

Las Naciones unidas en la Cumbre de la Tierra en Río de Janeiro en 1992, establecieron una Comisión para el Desarrollo Sostenible que puede tener un importante papel a la hora de impulsar este cambio de mentalidad. El resultado final principal de esta cumbre fue un documento titulado Agenda 21, en el que se define una estrategia general de desarrollo sostenible para todo el mundo, haciendo especial hincapié en las relaciones norte-sur, entre los países desarrollados y los que están en vías de desarrollo (Naciones Unidas 1992).

En la Unión Europea se elaboró en 1992 el V Programa de acción de la Comunidad en medio ambiente con el título de "Hacia un desarrollo sostenible». En este programa se decía «No podemos esperar... y no podemos equivocarnos», el medio ambiente depende de nuestras acciones colectivas y estará condicionado por las medidas que tomemos hoy. El V Programa reconoce que «el camino hacia el desarrollo sostenible será largo. Su objetivo es producir un cambio en los comportamientos y tendencias en toda la Comunidad, en los Estados miembros, en el mundo empresarial y en los ciudadanos de a pie». (Unión Europea 1992).

Sustentados en estos planteamientos nuestro objetivo de la investigación fue: Determinar si la Descentralización Macro Regional es estratégica para el Desarrollo Sostenible del Perú (1079-2015).

\section{Método}

\section{Tipo y nivel de investigación}

La Investigación es aplicada y de nivel descriptivo porque en base al conocimiento teórico se estudió empíricamente si la macro regionalización es una estrategia de desarrollo sostenible para el Perú. 
Participantes

1. Ámbito temporal y espacial del estudio Ámbito temporal del estudio: 1979-2014

Ámbito espacial del estudio: las regiones del Perú

2. Universo: 25 regiones del Perú

3. Unidad de análisis: la población

4. Método de muestreo. La población de estudio comprendió de 20 expertos sobre regionalización; que se eligió mediante el muestreo no probabilístico intencionado.

\section{Instrumentos}

\section{Técnicas recolección de datos}

Estuvieron orientados a determinar, si la macro regionalización es una estrategia de desarrollo sostenible para el Perú, y se utilizaron preferentemente los siguientes instrumentos:

- Análisis de contenido de los documentos sobre regionalización

- Técnica Delphi. Sucesión de cuestionarios que se aplicó a los expertos

- Se aplicó entrevista en profundidad a los expertos y líderes políticos de las regiones

- Se realizó el análisis de los datos secundarios, verificando las estadísticas sobre las regiones y los problemas que presentan.

\section{Procedimiento}

Procedimiento de recolección de datos

La orientación del presente estudio estaba destinada a que al final del proceso se logre verificar si la macrorregionalización es una estrategia de desarrollo sostenible para el Perú.

Las etapas del estudio fueron los siguientes:

Primera fase. Estudio preliminar

- Se seleccionó a 10 expertos en materia de regionalización para aplicar la técnica Delphi y a otros 10 entre autoridades de las regiones, líderes políticos y algunos ciudadanos notables de las regiones para aplicar las entrevistas en profundidad Segunda fase. Investigación de campo

- Se realizó el estudio aplicando los instrumentos de recolección de datos consistentes en:

- Un cuestionario compuesto por 5 preguntas abiertas que se aplicó a los 10 expertos utilizando la técnica Delphi.

- Una guía de entrevista para realizar las entrevistas en profundidad a las autoridades de las regiones, líderes políticos y algunos ciudadanos notables de las regiones seleccionadas intencionalmente mediante el muestreo no probabilístico

- La información fue procesada y nos generó una base de datos, de la que se extrajo la información cualitativa.

\section{Tercera fase. Procesamiento de los datos}

- Esta etapa se centró en analizar y valorar los datos obtenidos, con el fin de identificar y determinar si la macro regionalización es una estrategia de desarrollo sostenible para el Perú.

\section{Resultados}

\subsection{Situación actual de la regionalización en el Perú}

El contexto en el que se desenvuelve el proceso de regionalización en el Perú, se ha tornado en extremo complejo. Particularmente la presencia combinada de dos tendencias provenientes del escenario internacional es el origen de severas dificultades para los países en desarrollo. Estos procesos tienen que ver con:

1. la crisis de la producción alimentaria inducida por el uso creciente de tierras agrícolas para la producción de biocombustibles; $y$

2. el cambio climático, (calentamiento global) que afecta a todo el planeta y cuya intensidad y ritmo se muestran mayores de lo que inicialmente se había previsto (Grupo Propuesta Ciudadana, 2008: 34).

Otro lado, el desarrollo de las regiones está condicionado a una serie de problemas económicos, sociales y jurídicos que se presentan. Al respecto sostienen que: «La estabilidad macroeconómica es una condición necesaria, aunque no suficiente para el desarrollo de las regiones. La política económica debe plantearse como desafío central para evitar la polarización del país, lo que implica vincular la estabilidad con la modificación de la profunda desigualdad en la distribución de los recursos» (Azpur J., 2005: 17).

En esta dirección indican que "Aunque el Perú es abundante en recursos naturales; éstos se encuentran desigualmente distribuidos en su territorio. Esta es una de las causas de los profundos desequilibrios entre sus distintas regiones y localidades. Los ingresos por canon deben ser destinados por los beneficiarios a obras de desarrollo de investigación científica, técnica y mejoramiento del medio ambiente, de acuerdo a la 
presente ley y las respectivas leyes del canon por cada recurso natural. Debe ser competencia autonómica de los respectivos beneficiarios elegir en este marco de política sus planes de inversión». (PNUD, 2002: 89).

El Instituto Nacional de Estadística e Informática (INEI) entre el 2003 y el 2009, nos indica el crecimiento de algunas regiones: «La región de Arequipa ha crecido en $7.1 \%$ anual, cifra mayor al crecimiento nacional de $6.5 \%$. Es decir, en seis años su producción se ha incrementado en más de la mitad al pasar de 6 mil 652 millones de soles el 2003, a 10 mil 13 millones de soles el 2009 (...). La región de Ica ha crecido a una tasa de $10.8 \%$ anual, cifra mayor al crecimiento nacional que es de $6.5 \%$. Es decir, en seis ańos su producción casi se ha duplicado al pasar de 2 mil 980 millones de soles el 2003, a 5 mil 511 millones de soles el 2009 (...). La región de Huancavelica ha crecido a una tasa de 3\% anual cifra menor al crecimiento nacional que es de $6.5 \%$. Es decir, en seis años su producción casi paso de mil 200 millones de soles el 2003, a mil 433 millones de soles el 2009 (...). La región de La Libertad ha crecido a una tasa de $7.3 \%$ anual, cifra un poco mayor al crecimiento nacional que es de $6.5 \%$. Es decir, en seis años su producción casi paso de 5 mil 509 millones de soles el 2003, a 8 mil 444 millones de soles el 2009 (...). La región de Cusco ha crecido a una tasa de $9.9 \%$ anual, cifra un poco mayor al crecimiento nacional, que es de $6.5 \%$. Es decir, en seis años su producción paso de 2 mil 650 millones de soles el 2003, a 4 mil 664 millones de soles el 2009 (...). La región de Apurímac ha crecido a una tasa de 5.5 $\%$ anual, cifra menor al crecimiento nacional, que es de $6.5 \%$. Es decir, en seis años su producción paso de 570 millones de soles el 2003 a 786 millones de soles el 2009 (...). La región Cajamarca ha crecido a una tasa de $2.5 \%$ anual, cifra menor al crecimiento nacional, que es de $6.5 \%$. Es decir, en seis años su producción paso de 4 mil 239 millones de soles el 2003 a 4 mil 920 millones de soles el 2009 (...). La región de Piura ha crecido a una tasa de $7 \%$ anual, cifra mayor al crecimiento nacional, que es de $6.5 \%$. Es decir, en seis años su producción paso de 4 mil 732 millones de soles el 2003 a 7 mil 110 millones de soles el 2009 (...). El departamento de Lima Metropolitana ha crecido a una tasa de $7 \%$ anual, cifra mayor al crecimiento nacional, que es de $6.5 \%$. Es decir, en seis años su producción paso de 60 mil 541 millones de soles el 2003 a $91 \mathrm{mil}$ 357 millones de soles el 2009» (INEI,2014)
No se puede hablar del «milagro peruano» respecto a su crecimiento económico, porque este crecimiento no ha llegado a todos por igual y menos aún a las «zonas rurales». En tal sentido, las regiones seleccionadas continúan presentando vulnerabilidades frente a la crisis financiera internacional y peor aún, no presentan mejoras ante el desarrollo positivo de la actividad económica nacional (Nilton, 2011: 55 al 264).

Por otro lado, el crecimiento desequilibrado entre regiones y sectores productivos es el resultado del patrón de crecimiento basado en las exportaciones primarias y en la semi-industrialización dependiente, que ha privilegiado a la costa y a la selva y ha marginado a la sierra rural y a sus comunidades campesinas, principalmente a la economía andina y amazónica (Vegas, J., 2008: 177).

En Chile, se formuló e implementó un conjunto de políticas para intentar detener y revertir los efectos de un proceso de desarrollo territorialmente desequilibrado: inicialmente se establecieron zonas francas-con ventajas tributarias y arancelarias-, luego se identificaron regiones de planificación -agrupando a las preexistentes provincias-, para luego utilizar el enfoque del desarrollo regional polarizado, el desarrollo rural integrado y la urbanización del sector rural, entre otras» (Lira, L. \& otros, 2012: 3).

La asignación de recursos destinados a resolver los factores estructurales de la problemática regional pretende ser una acción de fondo para revertir los patrones de desarrollo desequilibrado" (Woo, G., 2002: 76)

El crecimiento desequilibrado entre regiones y sectores productivos es el resultado del patrón de crecimiento basado en las exportaciones primarias y en la semi industrialización dependiente, que ha privilegiado a la costa y que ha marginado principalmente a la economía andina y amazónica. Es urgente la descentralización y la regionalización como medidas para democratizar el desarrollo nacional que nos asegure necesariamente desarrollo (Vegas, J., 2013: 21)

El principal problema regional es el crecimiento desequilibrado entre regiones y sectores productivos, que es el resultado del "patrón de crecimiento» basado en las exportaciones primarias y en la industrialización dependiente, que ha privilegiado a la costa y a la selva y que ha marginado a la sierra rural (Vegas, J., 2006: 451).

Por otra parte, uno de los problemas de las regiones es el mayor indice de pobreza que muestran altos 
GRAFICO 1

\section{Incidencia de Pobreza Monetaria por grupos de departamentos, 2012 - 2013}

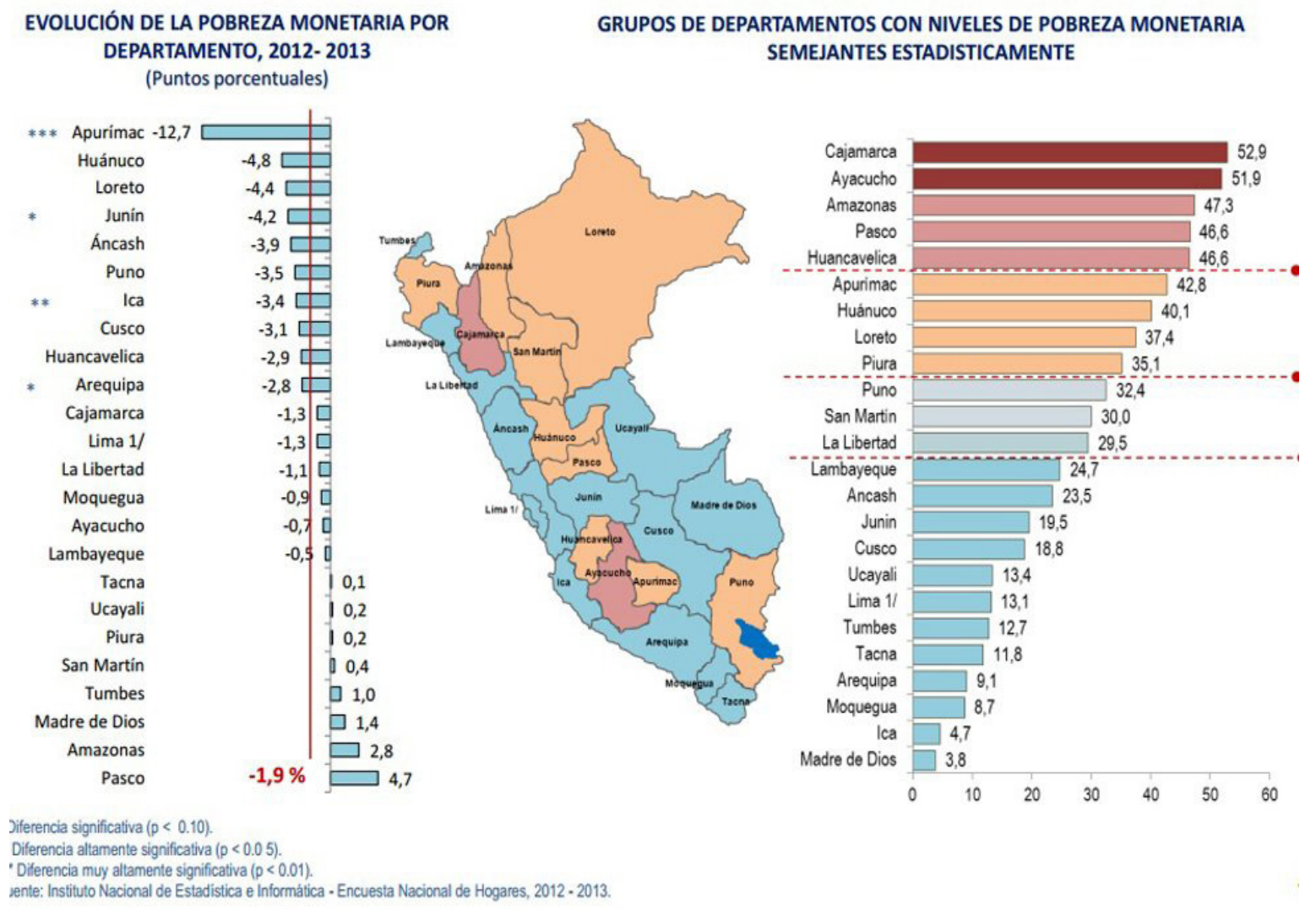

Fuente: Instituto de estadística e Informática. 2013.

niveles de desnutrición especialmente en las regiones de Huancavelica, Apurímac, Cajamarca, Ayacucho, Huánuco, Loreto, Ucayali y Cusco. También estas regiones son consideradas entre los grupos de mayor pobreza. (BCR, 2013:51). "Cabe destacar que en el año 2007 al menos cinco departamentos (Huancavelica Apurímac, Ayacucho, Cajamarca y Huánuco) registraban niveles de incidencia de pobreza por encima del 66\%, y el 2011, estos mismos departamentos ya mostraban niveles de pobreza por debajo del $56 \%$, lo que dice de los avances en materia de política social implementada en el periodo gubernamental anterior» (INEI, 2014: 10). Ver gráfico 1.

La región Huancavelica continúa siendo una de las más pobres del Perú y tiene graves problemas en salud y educación. Para revertir esta situación, más allá de otorgar subsidios a través de programas sociales, es necesario que el Gobierno regional invierta en capital humano a través de mejores centros educativos (de mayor calidad en maestros e infraestructura), inversión en infraestructura de transporte (mayor conectividad) y un mejor servicio de salud. Es urgente estructurar y ejecutar el presupuesto de la manera más eficiente posible (al igual que en Apurímac, Cajamarca y Ayacucho), para así atender mejor las necesidades básicas de la población.

Entre los ańos 2012 y 2013, la línea de pobreza extrema, presentó un incremento de 3,1\% a nivel nacional. A nivel de regiones naturales este mayor incremento se presenta fundamentalmente en la Sierra donde crece 5,0\%; por dominios se constata este crecimiento en la Sierra Rural y Sierra Urbana con un mayor incremento de 5,3\% y 4,6\%, respectivamente».

La pobreza extrema presenta mayores diferencias regionales que la pobreza: es casi 140 veces mayor entre la población rural que en Lima; y 13 veces más alta en la sierra y 9 veces mayor en la selva, que en la costa» (Aramburu \& otros, 2011: 63). A pesar que las tendencias favorables que muestran las principales variables económicas a nivel nacional, se observa en las 
regiones menos desarrolladas del país, la persistencia de comportamientos y patrones demográficos asociados a la pobreza y a las desigualdades e inequidades sociales y territoriales, que comprometen las posibilidades de un desarrollo descentralizado y equitativo» (Ministerio de la Mujer y Desarrollo Social, 2011: 11).

Como corolario a los problemas citados están la "corrupción de los funcionarios» Públicos en las regiones. A partir del año 1992, tras el auto golpe impulsado por el entonces Presidente Alberto Fujimori, se implanto un modelo político autoritario, que prometía acabar con la corrupción y el desorden que reinaba en todas las instituciones del Estado y de la Sociedad. Para ello se valió del desprestigio de los partidos políticos y de las instituciones como el Poder Legislativo, el Poder Judicial, los Gobiernos Regionales, a los que disolvió e intervino con la famosa comisión ejecutiva. Luego se dio la Constitución Política de 1993, para legitimar al régimen, en la cual se potenció la figura del Presidente de la República. En el ámbito regional, se constituyó los Consejos Transitorios de Administración Regional (CTAR), entes que se encargaban de la administración de los departamentos. En esta década se instaló un modelo político autoritario, que aparecía como eficiente en la construcción de obras de infraestructura, y no se visualizaba actos de corrupción.

Sin embargo, tras revelarse un video se observó como el asesor presidencial entregaba dinero en un maletín a un electo Congresista de la República, para que pase a la bancada oficialista; se causó una conmoción al país, que trajo como consecuencia la renuncia al cargo del entonces Presidente Fujimori. Luego de la caída del régimen se descubrieron una gran cantidad de actos de corrupción que involucraba a ministros, congresistas, militares, miembros de la prensa, sectores de la iglesia, entre otros. Ello ha generado una gran cantidad de procesos penales por delitos de corrupción, a tal punto que fue necesario crear entes jurisdiccionales especializados en el tema.

Después de la caída de Fujimori, a finales del 2001, Perú ingresa a una etapa de transición democrática con Valentín Paniagua, quien convocó a elecciones que fueron ganadas por Alejandro Toledo. Éste retoma el proceso de descentralización, con elecciones regionales en noviembre de 2002, instalándose los 25 gobiernos departamentales el 1 de enero de 2003 (Patiño, R., 2006: 20)

Los Gobiernos Regionales, tras la regionalización, reciben ingentes cantidades de dinero por concepto de canon, por lo que se ha convertido en un apetitoso botín para candidatos inescrupulosos que quieren llegar al poder con la finalidad de llenarse los bolsillos. En este aspecto, actualmente se puede destacar quelos Presidentes Regionales de Áncash, Cajamarca, Tumbes, Cerro de Pasco e Iquitos, se han visto envueltos en escándalos por delitos de corrupción, cometidos en el ejercicio de sus funciones. Los expertos en esta materia y como la del contralor Fuad Khoury Zarzar opinan que, a la luz de los graves y numerosos casos de corrupción que se están viendo actualmente en los gobiernos regionales, no es aconsejable la reelección inmediata de los presidentes regionales. Por lo que urge una reforma constitucional que elimine la reelección inmediata y ver la posibilidad de que se amplíe el periodo de cuatro a cinco ańos. Así mismo, señalan que hay 2.900 personas denunciadas por corrupción, de ellas 390 fueron juzgadas y solo 23 condenadas tienen cárcel efectiva.

Los actos de corrupción en el manejo de los fondos públicos por parte de los Gobiernos Regionales, como los casos de Áncash, Cajamarca, Tumbes, Cerro de Pasco e Iquitos, aparte del gran impacto mediático, ha revelado que las instituciones a cargo de la tarea de ejercer control y administrar justicia como la Contraloría General de la República, el Ministerio y el Poder Judicial, de las circunscripciones regionales, no han sido capaces de cumplir su función a cabalidad. Toda vez que los jueces y fiscales eran amenazados o captados por la red criminal, como el caso de Áncash. A esto se agrega para estos casos complejos no tenían la preparación y condiciones para afrontarlos con éxito. Sin embargo, el Poder Judicial y el Ministerio Público, se han creado entes especializados con sede en Lima, por lo cual ha sido posible procesar a los Presidentes Regionales de las regiones citadas, por delitos de corrupción durante su gestión pública. Así por ejemplo tenemos el caso de Viñas Dioses presidente de la Región Tumbes no solo está prófugo de la justicia, sino que es sospechoso de los delitos de colusión agravada por la venta de terrenos en Punta Sal. El 15 de junio del 2014 se dictó prisión preventiva e incluso se le acusa de colusión agravada, falsedad genérica y abuso de autoridad. En la región Loreto son procesados Iván Vásquez y otras siete personas por el delito de colusión agravada y peculado doloso por el caso de la planta de tratamiento de aguas. Por lo mismo que se le juzga por agrupación ilícita y malversación de fondos. Vásquez es además sospechoso del delito de administración fraudulenta por el caso 
Club Náutico. En Cajamarca, se procesa a Gregorio Santos, ex presidente regional, a José Panta y otros por el delito de cohecho pasivo propio, colusión desleal y asociación ilícita para delinquir. En la región Áncash, el presidente regional César Álvarez y 30 personas se encuentran comprometidos con la justicia. A la primera autoridad se le acusa por delito de homicidio calificado y asociación ilícita para delinquir. También se procesa a Álvarez, Juan Carlos Barrios, Jorge Luis Burgos, Olivares de la Cruz y aproximadamente 60 personas por el delito de peculado doloso y peculado, asociación ilícita para delinquir por el Caso La Centralita. En Pasco se encuentra procesado el presidente Kléver Meléndez por el delito de colusión, cohecho pasivo, asociación ilícita para delinquir y lavado de activos. Finalmente, en la región Ayacucho se procesa al presidente regional, Wilfredo Oscorima Nuñez, y otros por incumplimiento de deberes funcionales $y$ malversación de fondos. En Ayacucho, el Presidente Regional es procesado por delitos de malversación de fondos, incumplimiento de funciones y colusión.

Como se puede comprobar en los gobiernos regionales a parte de los problemas geopolíticos están presente de los problemas de pobreza, de corrupción, situación preocupante que merece una atención especial.

\subsection{La regionalización en el Perú responde a una estrategia geopolítica de integración de las regiones según sus posibilidades económicas y sociales}

La regionalización en en el Perú no responde a una estrategia geopolítica de integración de las regiones según sus posibilidades económicas y sociales, justamente esto es un problema que nos llevó a realizar las entrevistas en profundidad a los expertos en esta materia, líderes políticos y a los líderes representantes de la población de las regiones, ellos nos indican en su mayoría que fracaso del proceso de regionalización en el país y, algunos que son la minoría indican que está funcionando y sostiene que el principal motivo de esta situación es la corrupción y por la falta de una adecuada definición de las responsabilidades de las autoridades regionales. Así mismo señalan que la formación de microrregiones (donde algunas regiones afines o cercanas se juntan) no será la solución para los problemas de sus jurisdicciones.

Esto, nos permite asegurar que en el Perú la regionalización continúa siendo una tarea histórica, factible y sobre todo necesaria, que nos exige diseñar una estrategia geopolítica de integración según sus posibilidades económicas sociales y culturales que nos permitiría tener regiones integradas con desarrollo sostenible en virtud a ello tendríamos una verdadera descentralización. Los estudiosos como lo sustenta el Grupo Propuesta Ciudadana (2008: 44) y las entrevistas en profundidad que hemos realizado a los expertos, a los líderes políticos entendidos en esta materia nos permiten sostener que una verdadera regionalización debe estar basada en una estrategia geopolítica de integración de las regiones y dicha contribución se encuentra en varios niveles los cuales desarrollamos a continuación:

- Político: Las regiones formadas por integración de departamentos permitirán constituir núcleos de poder político e institucional de magnitud suficiente para actuar como polos compensatorios frente al enorme poder político y económico que ha acumulado Lima a lo largo de la historia. La regionalización apunta a la concentración de una masa crítica de competencias y recursos, las asienta en territorios (regiones) de tamaño adecuado y dota a estas entidades regionales de capacidades políticas de decisión para producir un esquema más equilibrado en el ejercicio del poder territorial.

- Económico: Las regiones integradas harán posible el aprovechamiento de potencialidades, manejo de recursos y proyectos que superan la dimensión local para generar impactos efectivos de carácter regional. Específicamente se asume que la escala regional es la apropiada para promover la competitividad de base territorial, ocupar y usar racionalmente el territorio, desarrollar capacidades empresariales y redes de innovación para enfrentar los desafíos nacionales y la inserción en el proceso mundial de la globalización.

- Territorial: El proceso de integración busca hacer converger las regiones políticas por crearse con los territorios económicos preexistentes o que se han venido formando en el país durante las últimas décadas. Se trata de cerrar la brecha que el Perú ha confrontado desde su origen republicano. A pesar de ser un país donde la geografía y la historia condicionan la existencia de territorios regionales muy diferenciados, éstos no han logrado una expresión política definida. No debe perderse de vista que el divorcio entre espacios políticos y territorios económicos es fuente de tensiones, 
ineficiencias y dificultades para la gestión del desarrollo nacional y regional.

La experiencia de estos últimos ańos demuestra que la integración de regiones es un proceso más complejo y prolongado que lo previsto inicialmente, en este contexto es necesario seńalar que aún permanecen los problemas y obstáculos que determinaron el fracaso en la consulta de año 2005, de tal manera resulta necesario e indispensable realizar un nuevo proceso estratégico del proceso de regionalización, los cuales se presentan a continuación:

- Adoptar una visión de largo plazo para la regionalización en el país.

- Apoyar la construcción económica de territorios regionales como condición previa a la constitución de regiones políticas.

- Inscribir la regionalización dentro de una estrategia de organización territorial en el país.

- Articular la dinámica regional con la dinámica local como condición clave para una regionalización sostenible.

- Flexibilizar el proceso político-institucional.

- Incluir a las provincias como unidad de referencia para el referéndum de las conformaciones de regiones.

En un sentido general, el papel asignado a las juntas de coordinación interregional es facilitar un proceso gradual, ordenado y sostenible hacia la conformación de regiones por integración de los actuales departamentos. Dicho de otra manera, las JCI están llamadas a concretar el modelo de regionalización flexible y abierto que aquí se ha planteado (Grupo Propuesta Ciudadana, 2008: 47).

La regionalización no ha logrado aún colocar en el país una agenda consistente para el desarrollo territorial. Pero si quiere trascender y perdurar como un instrumento útil para el país está obligada a corregir cuanto antes esta omisión. En este texto hemos procurado mostrar que precisamente en abrir las puertas a los enfoques territoriales de desarrollo radica el primer desafío de la regionalización (Santa Cruz, 2005: 89).

Finalmente es necesario señalar que para la gestión territorial el papel de las políticas públicas es decisivo. Por ello hay insistir en que una tarea de la máxima importancia es reforzar la capacidad del Estado peruano para formular políticas de carácter territorial, y superar los sesgos localistas que nos han restringido. Más allá de esto, las nuevas corrientes teóricas y las experiencias de otras latitudes, nos recuerdan que la sinergia entre actores públicos y privados, entre Estado, mercado y sociedad es la condición general para el desarrollo económico descentralizado. Es decir, para construir territorios ganadores frente a los retos de la globalización como lo asegura Santa Cruz (2005: 89).

\subsection{La regionalización de acuerdo a la situación geopolítica, económica y social es una posibilidad del desarrollo sostenible para el Perú}

Para determinar si la regionalización teniendo en cuenta la situación geopolítica, económica y social es una posibilidad del desarrollo sostenible para el Perú, se realizó mediante la técnica Delphi una sucesión de cuestionarios a expertos, que como resultado nos indican que los principales y permanentes desafíos que deberán enfrentar los gobiernos regionales para arribar a un desarrollo sostenido y sustentable de sus regiones, se consideran los siguientes:

- Consolidar y profundizar el Estado de derecho, la democracia y la soberanía regional.

- Mejorar la calidad de vida y el nivel de bienestar de amplios sectores secularmente marginados, olvidados y desvalidos.

- Desarrollar proyectos agroindustriales, mineros, turísticos y artesanales para generar empleo digno y con salario justo para la clase trabajadora.

- Hacer viable un mercado común interregional.

- Impulsar la ejecución de programas de cooperación técnica y científica, de producción de bienes culturales y de intercambio cultural-educativo a nivel de las regiones del país.

- Erradicar la pobreza, el narcotráfico, la contaminación ambiental y la violencia estructural en sus respectivas circunscripciones territoriales.

- Proteger y fortalecer el mercado interno regional y la banca comercial y financiera.

- Desarrollar políticas sociales para sectores más vulnerables.

- Fortalecer y consolidar las comunidades campesinas, comunidades nativas y las empresas cooperativas.

- Respetar los principios de no intervención y libre determinación de cada gobierno regional.

- Promover y estimular la participación de la ciudadanía, de las instituciones y organizaciones 
sociales, políticas, educativas y culturales y de todos los agentes económicos y sociales en el proceso de la cooperación e integración nacional e integración regional para el desarrollo humano integral.

- Afirmar y profundizar el rescate de la identidad cultural de la región y potenciar el uso de los recursos naturales

Y, para que sea real es importante crearle un Marco Normativo Nacional. Para fundamentar esta iniciativa, analizamos lo siguiente:

\section{a. Constitución Política del Perú (Ley de Leyes)}

Con relación a la Constitución Política del Perú, se toman en cuenta diversos artículos relacionados con la regionalización; así en principio tenemos el Art. 43, que hace alusión al Estado democrático de derecho, la forma de su gobierno; en este sentido se indica que el Estado, está dividido en función al principio de la separación de poderes, el cual es de importancia para el respeto de las funciones jurisdiccionales de cada órgano descentralizado, por cuanto está reconocido por la constitución, en donde ningún órgano del Estado, institución o gobierno (central regional o local) podrán usurpar las funciones de otro. El Estado es uno solo, representa al pueblo, pero dentro de su unidad territorial, el cual está dividido por la descentralización del poder, es por eso que cada región puede aplicar normas internas que estén acorde a la constitución y no sean contrarias a derecho.

La labor del Estado no debe quedar en solo la crear normas respecto a la Regionalización, sino ver que estas sean adecuadas para lograr una eficaz descentralización del Estado Peruano, es por ello que deben crearse no solo normas, sino políticas públicas que promuevan e impulsen a que se dé una verdadera descentralización de las regiones. Asimismo, encontramos al Art. 188 del mismo cuerpo legal, del cual podemos deducir que La descentralización es fundamental para el desarrollo del país, ya que no todo se concentrará en el Gobierno Central, con lo cual la competencia no estará en manos del mismo, sino de los Organismos Públicos Descentralizados, los cuales tendrá potestad solo dentro de su jurisdicción y esta función deberá estar acorde con la Constitución. Ahora los gobiernos regionales tienen la potestad de buscar el desarrollo de su región con lo cual se beneficia el país, ya que el Estado ya no tendrá que movilizarse a los lugares si no que estará representado por cada uno de los organismos que actúan con independencia.

Es preciso mencionar al Art. 189 de la Constitución, por el cual podemos concluir que El Estados debe crear mecanismos y normas que busquen proteger a la población de gobiernos regionales o locales corruptos que son un obstáculo al crecimiento de la economía y desarrollo de su región o localidad ya que al estar todos integrados al Estado como uno solo pero con jurisdicciones autónomas con lo cual no solo se afecta a dicha zona sino a todo el país, pero eso no quiere decir que el Estado deba intervenir directamente sino que debe crear normas que logren la eficiencia de los gobiernos descentralizados. Por tanto, el estado debe establecer y delimitar claramente las competencias del Gobierno Central, Regional para que se logre una gestión eficaz del Estado Peruano el cual sirva de impulso al crecimiento económico y desarrollo de las Regiones.

El artículo 190 de la Constitución al ser analizado, se tiene que no basta la creación de una región, si no se crea un plan estratégico de políticas públicas a nivel regional que busque el desarrollo en todos los sectores (salud economía trabajo infraestructura, etc.) por igual, es por eso que muchas de las regiones no progresan o el progreso no beneficia a toda la región generando un centralismo regional.

El desarrollo de una región se ve afectada, por la manera de cómo son dirigidos los recursos en materia de obras públicas o de infraestructura, por eso la utilización indebida sobre la asignación del canon a los gobiernos regionales no permite el desarrollo uniforme de éstas, ya que solo se centralizan en las zonas de explotación o zonas principales como las urbes o ciudades importantes, dejando en abandono a las zonas alejadas las cuales no se ven beneficiadas.

\section{b. Otras normativas nacionales}

Las normativas nacionales que se deben considerar es la Ley Orgánica de Gobiernos Regionales

\section{Ley $N^{\circ} 27867$}

Mediante su Art. 1 se deduce que la idea de descentralizar el poder, que solo recaía en el gobierno central, era el de evitar el crecimiento desigual que se daba en el país, el cual beneficiaba solo a las capitales sobre todo a Lima, es por eso que el Estado opto por descentralizar esa potestad que solo era de él, por lo 
cual transfirió no solo a los gobiernos locales sino a los regionales para que ellos busque el desarrollo de su propia región, ya que el Estado no podía estar en todos lados o resolver todos los problemas. Es claro que existe corrupción en los gobiernos regionales y que no existe una adecuada fiscalización en estas gestiones por parte de la Contraloría, por lo cual su labor de fiscalización no es eficaz para evitar que se realicen estos tipos de actos que afectan el desarrollo de la misma región

De la misma manera su Art. 2 nos deja en claro que los gobiernos regionales, son los representantes del pueblo, y solo desarrollara su gestión dentro de la circunscripción de su territorio regional, ya que fueron elegidos por este, para que los represente con la finalidad que en su gestión logren el progreso, desarrollo y crecimiento económico de la región, beneficiando a toda la población que se encuentre dentro de su territorio regional. Su autonomía no depende de otras regiones o del gobierno central, sino de sí misma, el cual le facultad a tomar las medidas adecuadas para cumplir con un gestión eficiente y eficaz para satisfacer las necesidades de la población.

Mientras que el Artículo 3 del mismo cuerpo normativo, da a conocer que los gobiernos regionales solo pueden actuar dentro de sus respectivas circunscripciones territoriales, esto quiere decir que no podrán entrometerse con la gestión de otra región o tomarse potestades que no le corresponde sobre una zona de otra región.

Los problemas de competencia territorial entre regiones se podrían evitar si se regula de manera adecuada la delimitación territorial para lograr una Regionalización eficaz.

\section{Ley $N^{\circ} 24650$}

Otro norma referente a la regionalización es justamente la Ley de bases de la regionalización Ley $\mathrm{N}^{\circ} 24650$, la cual en su Artículo 1, nos aclara que el conjunto de regiones descentralizadas, con gestiones eficientes es de suma importancia para el desarrollo del país, las cuales deben trabajar con la finalidad de desarrollar sus regiones, por lo cual podrán posibilitar que cada una de ellas puedan generar sus propios ingresos, de esta manera permiten que el Estado pueda dirigir y fortalecer otros sectores, como la educación, seguridad ciudadana, seguridad nacional, etc., pero la realidad es otra, ya que la corrupción existente en los gobiernos regionales solo causan un innecesario gasto publico dirigido a su propia persona o a favorecer a terceros con transferencias astronómicas de dinero.

La regionalización no se está cumpliendo con la finalidad para las que fueron creados los Gobiernos Regionales, ya que se evidencia que muchos presidentes regionales se encuentran siendo procesados por delitos de corrupción y otros están siendo fundadamente investigados, con cual se afecta directamente la gestión del órgano regional, consecuentemente a la población asentada en sus territorios.

Otro de los graves problemas, es que no se está aprovechando los recursos que provienen de la asignación del canon, ya que se entrega sumas de dinero cuantiosos a personas, autoridades y organismos públicos sin capacidad de gestión más grave aún sin fiscalización cómplice, evidente porque no se están desarrollando de manera uniforme las regiones, ni siquiera las ciudades y lugares de explotación de minerales e hidrocarburos beneficiarios con la asignación del canon. Se está desatendiendo necesidades básicas de la población, entre otras causas porque no existen verdaderas políticas publicas regionales, para utilización y aprovechamiento de estos recursos.

Por lo expuesto, para que las Regiones del Perú se orienten hacia el Desarrollo Sostenible requiere de modificaciones normativas que no contravengan la Constitución Política del Estado, que no afecten la autonomía de los gobiernos regionales, que se promueva la generación de sus propios recursos y no solo limitarse al presupuesto del erario nacional, por el contrario la eficaz gestión de los gobiernos regionales que beneficien no solo a las regiones sino a todo el país, generando puestos de trabajo, crecimiento económico, mejoramiento de los servicios básicos y que las regiones se desarrollen uniformemente para el bien común.

\section{Discusión}

La regionalización como sostiene Gonzales de Olarte (1989: 8), no es necesariamente una condición previa para el desarrollo ni para la desconcentración económica, en la medida en que no ocurran cambios en la estructura económica a nivel espacial que modifiquen el actual patrón de crecimiento y distribución. Aunque sí es una de las posibilidades más importantes para democratizar el Estado y cambiar la relación Estadosociedad, puesto que permite la creación de nuevas instituciones capaces de descentralizar recursos y 
capacidades de decisión. Sin embargo, su importancia radica en la forma como se van a relacionar a partir del mismo, el Estado y la sociedad, puesto que surgirán nuevas formas de intervención de los últimos que genere la toma de decisiones y la utilización adecuada de los recursos que son designados para los mismos. Consideramos que la regionalización es un proceso que en muchos países en los que se ha instaurado, requiere de una constante colaboración y participación, en cuanto a la toma de decisiones y distribución de los recursos económicos repartidos para el lugar geográfico donde se ubican. En conclusión, señalamos que la regionalización si bien no es considerada como un procedimiento necesario para el desarrollo del país, por el autor en comentario, sin embargo, en nuestro país su imposición, lograría la distribución de funciones adecuadas, pero con mayor fiscalización para la satisfacción de las necesidades básicas de cada lugar. Es necesario que el marco normativo relacionado con la regionalización plasme todas las situaciones posibles, a fin de poder estar frente a una eficaz descentralización del Estado Peruano con lo que coincidimos con Azpur (2005:16).

En suma, el objetivo último de la regionalización es generar un nuevo ordenamiento territorial que permita reducir las profundas desigualdades espaciales que se originan en la gran concentración del poder económico y político de nuestra sociedad. Una visión de estas características nos permite entender que solo estamos dando los pasos iniciales de un proceso que se proyecta en el mediano y largo plazo. Transformar una sociedad tan centralista como la peruana requiere cambios sostenidos en la estructura económica, política, institucional y cultural. En ese sentido, la regionalización debe llevarse adelante como una política de Estado. Uno de los cambios radicales que trae consigo la regionalización es justamente lograr el ordenamiento territorial, sin embargo, es preciso tener en claro que ello se dará en un largo plazo, ya que es necesario tener presente que dicho cambio surgirá en la medida que se adecuen los aspectos económicos y políticos al mismo.

La regionalización de nuestro país, se considera como un avance al denominado centralismo que vivimos hoy en día, donde se observa la concentración del poder en los, ámbitos económico, político, institucional, etc., en un solo espacio geográfico.

La regionalización es un proceso que se ha instaurado dentro de nuestro país hace muchos años atrás, la falta de una regulación adecuada en referencia a la delimitación territorial y sus competencias no permiten una descentralización eficaz, con autonomía política, económica, administrativa, etc. Lo que coincidimos con Benavides, G (2012:70) cuando asegura que «el papel de los gobiernos radica en asegurar un clima de inversiones competitivo, definir reglas y procedimientos administrativos para los procesos de participación ciudadana y tener la capacidad de sumar esfuerzos y establecer alianzas constructivas con las empresas mineras y organizaciones civiles». Como podemos apreciar Benavides, nos da a conocer una de las principales funciones que deben realizar los gobiernos, ya sean locales o regionales, al encontrarse dentro de un ámbito donde se ha plasmado la regionalización.

Las funciones de los gobiernos, una vez que se ha instaurado el proceso de regionalización, es justamente lograr la inversión de diversos entes económicos dentro de la unidad territorial donde se encuentran, para lo cual es necesario establecer todos los parámetros necesarios con el objetivo de estar frente a una negociación eficiente, en satisfacción y cumplimiento cabal de las necesidades de los ciudadanos. Además, a esto es importante no dejar de lado la falta del establecimiento adecuado de las competencias, tanto del Gobierno Central, local y regional.

Finalmente es necesario señalar que para la gestión territorial el papel de las políticas públicas es decisivo como lo sostiene Santa Cruz (2005: 89) con lo cual coincidimos que es necesario reforzar la capacidad del Estado Peruano para formular políticas de carácter territorial, y superar los sesgos localistas que nos han restringido. Más allá de esto, las nuevas corrientes teóricas y las experiencias de otras latitudes, nos recuerdan que la sinergia entre actores públicos y privados, entre Estado, mercado y sociedad es la condición general para el desarrollo económico descentralizado. Es decir, para construir territorios ganadores frente a los retos de la globalización. Santa Cruz (2005), indica que es necesaria la implantación de políticas públicas que tengan que ver con la gestión territorial, siendo esta una de las características básicas del proceso de regionalización. En síntesis, las principales acciones que se debe tomar en consideración dentro del proceso de regionalización es justamente la gestión territorial, así como la desconcentración económica y política; por ello es necesario la instauración de políticas públicas que busquen una fiscalización eficaz a las acciones que se realizan en torno a la misma, a fin de poder 
cumplir con el fin único de la regionalización y sobre todo lograr establecer una relación adecuada entra la Sociedad y el Estado propiamente dicho.

Finalmente, Khoury Zarzar (2014) Contralor señala que la descentralización fiscal y la transferencia de recursos no se adecúan a las necesidades de gastos de los gobiernos regionales y que la forma de distribución del canon ha distorsionado los presupuestos. «Hay demasiado dinero en algunas zonas que no saben en qué gastar, y otras zonas con más necesidades que no reciben casi nada».

Por tanto, dentro del proceso de regionalización no se efectúa una adecuada distribución de los recursos, dotar de capacidad de gestión a los actores, oportuna fiscalización de los mismos que no se ha dado para evitar la proliferación de la corrupción de tal manera se impulse el desarrollo integral del Perú.

\section{Conclusiones y recomendaciones}

\section{Conclusiones}

1. Las regiones que conforman el territorio del Perú son un calco del Gobierno Central ya que la inoperancia e ineficacia de las gestiones para resolver los problemas sociales y la creciente inseguridad ciudadana, y a todo ello se suma los casos de corrupción de los presidentes regionales en donde las regiones no se han desarrollado o se da un desarrollo desigual de la región ya que es inadecuada las normas que regulan la regionalización afectando la eficacia de la descentralización del Estado peruano

2. La autonomía que tienen las regiones, para realizar libremente su gestión, se circunscribe solamente a su territorio, es por eso que la regulación de la delimitación territorial es inadecuada, dando como consecuencia una ineficaz regionalización.

3. La importancia de que se respete la autonomía de cada órgano de gestión pública (Gobierno Central, Gobierno Regional y Gobierno local), radica en la competencia que tienen sobre su territorio donde se circunscribe su gestión, es por eso que estas competencias no han sido claramente establecidas y delimitadas, con lo cual genera una ineficacia gestión del Estado Peruano.
4. Es sabido que las regiones, no distribuyen de manera uniforme el gasto público, ya que solo son beneficiadas las ciudades principales, desatendiendo a los poblados que se encuentra alejadas de las grandes urbes, o que el dinero es dirigido a cuentas propias o terceros, beneficiando a empresas inflando de esta manera el costo de una obra, con lo cual la asignación del canon no es utilizada para el desarrollo uniforme de los Gobiernos Regionales.

5. Las constantes noticias sobre la corrupción existente sobre las gestiones de los gobiernos regionales, la cual evidencia que no existe una verdadera fiscalización por parte de la Contraloría que debería realizar sobre la gestión de los Gobiernos Regionales por lo cual su labor no es eficaz para evitar que se realicen actos de corrupción.

6. Se ha determinado que la Macro Región es la más adecuada para el desarrollo sostenible del Perú.

\section{Recomendaciones}

Con el propósito de lograr mayor claridad en torno a la regionalización, es la creación de Macro Región y para que sea real es necesario cumplir lo siguiente:

1. Debe crearse normas para que la regionalización sea eficaz para la descentralización del Estado Peruano.

2. Se debe regular la delimitación territorial para una eficaz regionalización.

3. Se deben crear normas que establezcan y delimiten claramente las competencias del Gobierno Central, Regional y Local para que se dé una gestión eficaz del Estado Peruano.

4. Se deben crear normas y políticas públicas para la utilización y aprovechamiento de los recursos de la asignación del canon a los gobiernos regionales para un desarrollo uniforme de estos.

5. Se debe crear normas en razón a una fiscalización a la mala gestión de los Gobiernos Regionales, la cual deberá ser clara, ya que no debe intervenir las gestiones de estos, la cual deberá estar dirigida a evitar los actos de corrupción devenidos por la gestión de estos órganos públicos descentralizados. 


\section{Referencias bibliográficas}

Aramburu, C. y otros (2011). Políticas sociales y pobreza. México: Edit. Economía y Sociedad.

Azpur, J. (2005). Descentralización y regionalización. Lima: Grupo Propuesta Ciudadana.

Benavides, R. (2012). La minería responsable y sus aportes al desarrollo del Perú. Lima: Biblioteca Nacional del Perú.

BBC News (2007). «Fujimori: Decline and fall». The New York Times.

BCR (2013). Informe económico y social, Región Tacna. Lima: Banco Central de Reserva.

Dublín (1987). Comisión Mundial sobre Ambiente y Desarrollo (Comisión Brundtland).

Gonzales de Olarte, E. (1989). Problemas económicos de la regionalización en el Perú. Lima: IEP Ediciones.

Grupo Propuesta Ciudadana (2008). Regionalización herramienta clave para descentralización y la gestión territorial. Lima: Red participa Perú.

INEI (2014). Evolución de la pobreza monetaria 2009-2013. Lima: Instituto Nacional de Estadística e Informática.

Khoury, F. (Miércoles 11 de junio de 2014). «El proceso de regionalización no tuvo éxito». El Comercio. Lima.

Lira, L., y otros (2012). El proceso de regionalización en Chile. Santiago: Centro de Estudios Regionales, U. de los Lagos.

Marcos, J. (1996). Las comunidades campesinas en el proceso de regionalización del Perú. Lima: Nueva Sociedad.

Ministerio de la Mujer y Desarrollo Social (2011). Plan nacional de población 2010-2014. Lima: Ministerio de la Mujer y Desarrollo Social.

Monge (2008). Los gobiernos regionales. Lima: Centro de Estudios y Promoción del Desarrollo.
Naciones Unidas (1992). Cumbre de la Tierra. Río de Janeiro: NNUU.

Nilton, Q. (junio de 2011). Evolución económica de las regiones del Perú: crisis y post-crisis. Lima: Grupo Propuesta Ciudadana.

O'Neill, K. (2000). Tugging at the Purse Strings: Fiscal Decentralization and State. Discretion. Paper presented at the 2000 meeting of the Latin American Studies.

Patiño, R. (2006). La descentralización del Perú 2002-2005Su implementación dentro de un gobierno divido. México: FLACSO

Programa de las Naciones Unidas para el Desarrollo (PNUD). (2002). El canon como fuente de financiamiento para el desarrollo regional y local. Lima: Cuadernos PNUD.

Unión Europea (1992). «Hacia un desarrollo sostenible». En el V Programa de Acción de la Comunidad en medio ambiente.

Santa Cruz, F. (2005). Desafio y tareas de la regionalización en el Perú de hoy. El proceso de regionalización en el Perú: realidades y desafios. Lima: CEDEP:

Schönwälder, G. (2004). Linking Civil Society and the State: Urban Popular Movements, the Left, and Local Government in Perú, 1980-1992 (en inglés). Pensilvania: Penn State University Press. ISBN 0-271-02534-4

Vegas, J. (2008). Regionalización, comunidades campesinas y desarrollo. Revista de Antropología. Lima: UNMSM.

Vegas, J. (2013). Primero descentralizar, después regionalizar. Investigaciones Sociales, № 25. Lima: UNMSM.

Woo, G. (2002). La regionalización: nuevos horizontes para la gestión pública. Guadalajara: CUCEA. 